\title{
Confronting ecological futures: global environmental crises in contemporary survival quests for young adults
}

http:/ / urn.kb.se/resolve?urn= urn:nbn:se:sbi-23

Abstract: This paper examines representations of societal concern in the futuristic ecological disaster fictions of three British authors: Julie Bertagna (Exodus; Zenith), Jan Mark (Riding Tycho; Voyager) and Marcus Sedgwick (Floodland). The depicted refugee journeys in these futuristic worlds speak into a growing global disquiet that surrounds current historic events. Environmental crises that ground the emergent world orders of depicted future societies set the scene in each coming of age frame: each survival quest embeds social and cultural issues recognisable to contemporary audiences in futuristic representations of changed world orders, limited resources, and isolated communities.

Authors resist the mythic frame of a traditional quest journey - a call to journey, the engagement with growth through a road of trials and then celebrations in a return to home territory: their conclusions offer limited resolutions, the struggle to survive entrenched as a linear path. Because authors link depictions of the refugee subject with environmental degradation, apocalyptic scenarios that signify the devastating consequences of global environmental crises provide an ecocritical platform from which each author situates a discourse of protest. Interrogating contemporary political positions of ambiguity and denial their novels profile social justice issues experienced by refugee populations in contemporary society.

Keywords: Bertagna, Mark, Sedgwick, ecocriticism, refugees, postdisaster fiction, displacement, transformative utopianism.

During the past decade media images of refugee journeys that inform futuristic children's literature have been grounded increasingly in a global discourse that centres upon predictions of environmental 
crisis. Embedded within the event frame of postdisaster survival quests, this broad ecocritical agenda indicates rising societal concerns that current environmental changes to Earth's climate may be irrevers-ible. This same intention to interrogate contemporary ambivalence toward global degradation is evident in the work of three British authors whose novels maintain an ecocritical agenda: namely, the connection between depleted Earth scenarios and environmental migration issues has been clearly articulated. Julie Bertagna (Exodus and Zenith),Jan Mark (Riding Tycho and Voyager), and MarcusSedgwick (Floodland) construct survival quests imbued with refugee images of childhood displacement and consequential oceanic journeys.

The past decade has seen an increase in postdisaster survival stories which focus upon futuristic representations of environmental disaster. A "rapidly increasing concern with the threat of climate change" which Stephens notes as a "key cultural pressure" is expected to strengthen the field of ecocritical studies in children's literature (Stephens, 2009, 2.2, vii). Authors of such fictions not only identify social and political issues of environmental injustice that dominate the popular imagination, but also confront societal ignorance. While environmental devastation is a common theme in post-disaster fiction after 1990 and many such fictions address a diverse range of conservation factors, they fail to connect ecological issues with a recognisable, already identified, human toll. The novels chosen for this paper identify environmental issues, but the authors also interrogate societal ignorance because their fictions connect an ecocritical platform to issues of legal representation commonly experienced by environmental refugee populations in contemporary societies. Even as their future worlds are beset by the effects of global ecological devastation, the refugee journeys of female protagonists draw upon a survival motif as old as tales of ancient floating arks. Biograph-ical refugee narratives may commonly depict migratory voyages in this manner, but the selected works of Bertagna, Mark and Sedgwick connect possible future global changes with this motif: contemporary ecocritical perspectives articulate the plight of migrating refugee subjects for whom an oceanic voyage signifies survival.

\section{Environmental fragility and human vulnerability.}

The environmental issues that ground these refugee quests replicate eco-political debates concerning anthropogenic changes to Earth environments. Within the past decade, global warming 
debates have made prominent what Bertagna identified as the 1999 beginning inspiration for her series: "A tiny snippet in a newspaper. It was a momentous piece of news....about terrified islanders in the Pacific Ocean who were losing their land to the rising sea" (Zenith, 2007, 343). Bertagna's recognition of imminent disaster has been confirmed by a recent report (Warner et al, 2009) which identifies the effect of rising sea levels upon island nations as a significant cause of contemporary displacement. This awareness of environmental fragility, which is similarly evident in the novels by Sedgwick and Mark, has created a deliberate link between human vulnerability and environmental devastation in depicted refugee journeys. Just as child focal-ising agents symbolise an endangered and displaced humanity, the futuristic imaginary connects human survival with a global environmental vulnerability. In Bertagna's protagonist, Mara, the voice of future childhood articulates the consequences of present ambival-ence to environmental action even as Bertagna's flooded world aptly portrays the same ambivalence in the Sky City dwellers' ignorance of refugee crises outside the exclusion zone of city walls. In Jan Mark's series, the depicted recognition of environmental issues following Earth's ecological ruin fails to provide significant cause for conserv-ation, in that the new planetary settlement (Demeter) struggles to maintain ecological and democratic principles that would prevent another disaster. In a punitive societal framework where political unrest prevents the maintenance of effective ecological controls, Mark's refugee protagonist, Demetria, victim of an abusive patriarchal society, escapes her island's oppressive system on a floating log swept along by the ocean current, Tycho (Riding Tycho). But, when rescued, her plight as a refugee "alien" (Voyager) places her in more danger than the four week oceanic journey that reduced her to an unrecognisable mute, a sunburnt skeletal figure (Riding Tycho). Sedgwick similarly contrasts Zoe's refugee experience on a small island refuge (Cathedral Island) where depleted provisions result in an escalation of gang violence, with that of her parents' passage to safety. In representing the interconnectedness between human survival and ecological practice, the authors clearly articulate both the vulnerability and the agential behaviours of child refugee protagonists.

\section{Ecocriticism as an ethical reorientation.}

The quest structure, with its grounding patterns of emergent subjectivities (McCallum 2006, 218; 1999, 9) may function, as Hubert Zapf 
suggests about literature more generally, "as the symbolic medium of a particularly powerful form of 'cultural ecology'” (Zapf 2009, 852). Zapf argues that literature, as a form of "cultural knowledge" or as a "reintegrative discourse" by which different disciplines and cultures may bereunited (Zapf 2009,865), may inform the interactions between humankind and the planet's ecological systems because language itself permits the integration. Ecological imaginings in children's quests, particularly those in which primary focalising agents depict refugee perspectives, suggest such a "reintegrative discourse" because of their focus on the social, political and ethical issues surrounding human survival within a global ecological system. Thus the novels I am discussing establish what Zapf terms "an ethical reorientation" whereby the human capacities for child subjects to negotiate changing environments are achieved through a relational connection that affirms ethical value in an "obligation toward the other" (Zapf 2008 , 854). Similarly, the ecocritical frame of these novels argues that a connection between humankind and other living systems implies an obligation to maintain the planet for future habitation. Thus ecocritical views are conveyed through a dystopian lens that reflects refugee issues of exclusion whilst a future utopian vision is expressed by subject transitions: the development of agential behaviours, human resilience, relational strategies and negotiation of social justice issues provide the impetus for transforming acts in each quest.

When narrative tension is used to create a dialogue between utopian and dystopian frames, environmental discourse can "shape attitudes by contrasting utopian and dystopian possibilities", as Bradford, Mallan, Stephens and McCallum have demonstrated (Bradford et al, 2008, 90). Identified as a "transformative utopianism" (ibid, 6) the merged generic pattern in children's fiction is differentiated from more nihilistic dystopian traditions of adult science fiction (Moylan, 2000, 180-182; Baccolini \& Moylan, $2003,2-3)$ as both utopian and dystopian themes may be used simultaneously to create new frames of reference. Bertagna, Mark and Sedgwick employ this strategy to balance the plight of their refugee subjects with the ecocritical interrogation inherent in their novels. Although Sedgwick's novel constructs a less complex quest structure than those of Mark and Bertagna, the experiences of loss and displacement convey dystop-ian themes that imply a failure of utopian ideals as vulnerable child subjects are left in isolation. In postdisaster fictions, ecological themes may appropriate this thematic tension for critical purposes; for example, contemporary utopian visions and concomitant world orders may be interrogated or even 
contested as dystopian when viewed through the marginal lens of the displaced. Mara's experiences within the utopian sky city, New Mungo (Bertagna's Exodus), interrogate the validity of societal protectionist policies by exposing the truth about the city's refugee exclusion zones to her cyber associate and lover, the city born "Fox". But "Fox" fails to understand her contestations of social injustice until he views the deadly effects of the city's ref-ugee slave trade by which sky city oceanic platforms have been constructed. In Voyager, a similar confrontation occurs when Mark's protagonist, Demetria, expecting to find refuge in the utopian society of Baltica, is instead exposed to the rigid totalitarian regime of Laur-entia where she is arrested upon arrival. Constructing an ongoing dialogue between utopian and dystopian frames the author reveals the political aspects of environmental refugee concerns in a manner that clarifies contemporary social justice issues and the systems by which such injustices might be legalised.

\section{Contemporary ecocritical perspectives}

Realistic descriptions of refugee voyages in the post-disaster novels of Bertagna, Mark and Sedgwick enhance narrative authenticity because their utopian and dystopian themes connect contemporary environmental concerns with fictional representations. Engagement with environmental issues has been negotiated in these novels in ways that seek to retain credibility through association with a contemporary discourse of protest. Settings are grounded in isomorphic connections to contemporary events and correspond with current predictions that environmental devastation will occur. This engage-ment with ecological disquiet is most evident when authors spec-ulate upon future consequences of global climate change and the impact upon human habitation: less than one hundred years hence, Sedgwick's flooded lands accommodate current climatic modelling for the twenty-first century; Bertagna's Exodus begins with images of accelerating global inundation at 2099; Mark's new planetary settlement, founded around 100 years after Earth becomes uninhabitable, has become politically divided three centuries later as the same eco-political arguments re-appear.

Whilst refugee perspectives also use the interrogative strategy of confrontation - contemporary utopian visions embedded in the settings are identified and interrogated through the dystopian lens of the displaced-the relational connections established among similarly marginalised characters create opportunities for transforming 
action. Within the interactive space that is constructed between dystopian and utopian visions, each refugee protagonist is represented within social spaces that either limit or empower an ongoing survival journey. Of the selected post-disaster novels, the series, Exodus/Zenith, (to becompletedinlate2010) providesan excellent example of transformative interactions: Bertagna's protagonist, Mara, is aware that none of the refugee groups have a future in New Mungo. The fringe dweller boat people outside city walls, the "Treenester" families and "Ratbashers" (orphaned children) hiding in the remnant underworld of New Mungo, and the enslaved workers locked in the unfinished towers of the sky city, are all condemned to starvation through exclusion from the city's well guarded refuge. Mara's initial cyber link and later deepening relationship with Fox (grandson to the founder architect) provides access not only to

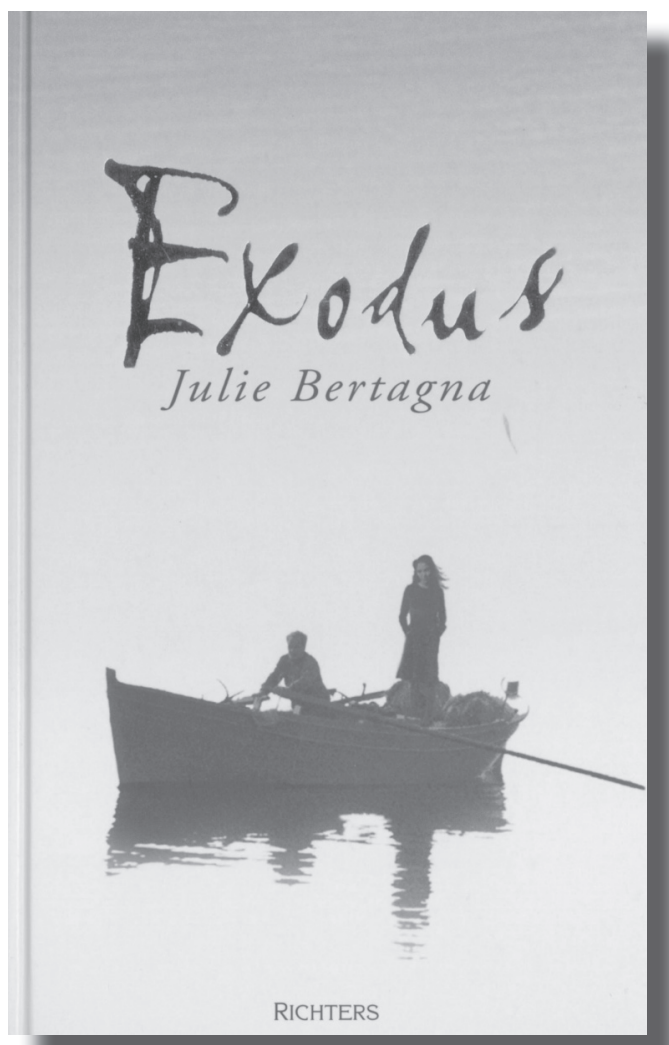

Cover of the Swedish edition of Exodus by Julie Bertagna. Richter, 2004 safe passage within New Mungo, but also to the vast shipping fleet. The decision to set out by ship thus, in Zenith, releases some refugee groups to seek refuge in lands to the North, once covered by ice. Mara's intimate connection with Fox, severed by his decision to remain, as an activist, near the sky city, is replaced by further participation within other refugee groups and continues to develop throughout the character's quest for survival. This awareness of social interaction and its responsibilities reflects the "transformative utopian" frame that tends to develop from merged utopian/dystopian themes in these novels (Bradford et al, 2008).

\section{Historic perspectives ground ecocritical frames.}

Mentor figures are similarly employed as a relational strategy in each of the survival quests. Mentor figures maintain connection with an historic past and provide an informational conduit that connects 
protagonists with historic knowledge and alternate perspectives. Mentors also broaden the narrative point of view of child focalising agents because historic perspectives invariably provide strengthened sites of resistance that affirm the dystopian aspects of represented world orders in each novel. In Floodland Zoe listens with interest to the tales of old William, whom many consider to be senile. But these fragments of memory provide hope for Zoe that a small boat, directed west, would reach higher land. So although interrogative strategies of confrontation and protest are most prominent in these survival journeys, depictions of relationship and participation, however marginal, provide an important framework for future hope. In this manner the narrative tensions constructed between a failed utopian vision and an environmental critique speak back from future dystopian worlds into historic discourses of the present.

\section{Negotiating apocalypse.}

It is important to note here that the inclusion of environmental protest within postdisaster genres can be problematic: postdisaster settings, event structures and resolutions must negotiate the credibility problems endemic to the genre (Stephens 1992, 126130). If the consequences envisioned for human civilization are too extreme, or the proffered solutions too simplistic, an apocalyptic vision will fail to integrate the environmental critique. As Garrard $(2004,106)$ suggests, apocalyptic environmentalism, as a discourse of protest, has the potential to polarize environmental debates because extreme scenarios may easily be identified as unsupportable and lacking in credibility. Postdisaster fictions depicting transformative possibilities through an ecocritical lens must negotiate these extremes in order to retain integrity. To successfully negotiate the credibility issue postdisaster novels construct narrative settings which connect authorial voice to an ecocritical discourse that is already informing contemporary political debates. In the futuristic quests written by Mark, Bertagna and Sedgwick, clear connections link fictional settings with contemporary media reports and thus reinforce narrative credibility because readers are familiar with an already activated critical discourse - one that is affirmed through metaphorical representations of contemporary events.

Thus, in order to gain authenticity, a threefold representational strategy becomes evident in the authors' depictions of environmental issues. First, dystopian settingsimply a critique of failed human societal systems: the destructive capacities of contemporary world orders are exposed and ethical issues posited, namely, the acceptance of further 
marginalisation of the innocent, the use of control and surveillance, and an avoidance of social and political responsibilities toward displaced subjects. Second, as mimetic representations of current global systems of power, representations that convey utopian vision in futuristic world orders are interrogated as dystopian because focalised by refugees; and finally, the historic past is reviewed by remnant voices of elders, voices that carry cultural tellings, remembered events, and new narratives affirming humankind's survival. This evolving ecocritical frame extends established patterns in children's literature where more local concerns such as pastoral and wilderness preservation or relationships between human and animal beings have been prominent (Dobrin \& Kidd, 2004, 3-8).

\section{Dystopian settings and societal failures.}

Futuristic settings in Sedgwick and Bertagna begin with scenes of distress as rising ocean levels force evacuating groups to escape by sea. Marcus Sedgwick's first novel, Floodland, depicts a sudden crisis as low lying areas of the British east coast become flooded. As a postdisaster fiction thematically aligned with environmental theories of global warming, Floodland predicts national consequences for rising ocean levels, especially the loss of major cities, primary industries and major infrastructure. Societal critique and depicted consequence for a flooded planet have been simplified, however, because Sedgwick addresses a younger audience than the fictions of Mark and Bertagna. Published at the turn of the millennium, the novel also predates global responses to terrorism and thus does not feature high levels of control and surveillance that dominate the new world orders of Exodus/Zenith (Bertagna) and Riding Tycho/ Voyager (Mark). In Bertagna's futuristic series apocalyptic settings convey the distress of community displacement as global flooding inundates whole continents. Bertagna's prelude establishes her intention: speaking from the future into present decision making, the author directs her telling as an address at the "dawn of the world's drowning" (Bertagna 2002, i). The depicted social and political consequences of a global ecological disaster direct the reader toward reflective observation: "Stand at the fragile moment before the devastation begins, and wonder. Is this where we stand right now, right here on the brink?" (Bertagna 2002, i).

One century hence, Bertagna's apocalyptic scenes portray the threefold crisis assessments identified clearly in a recently published Refugee Studies Research Guide (Boano 2008, 8-9) indicating that 


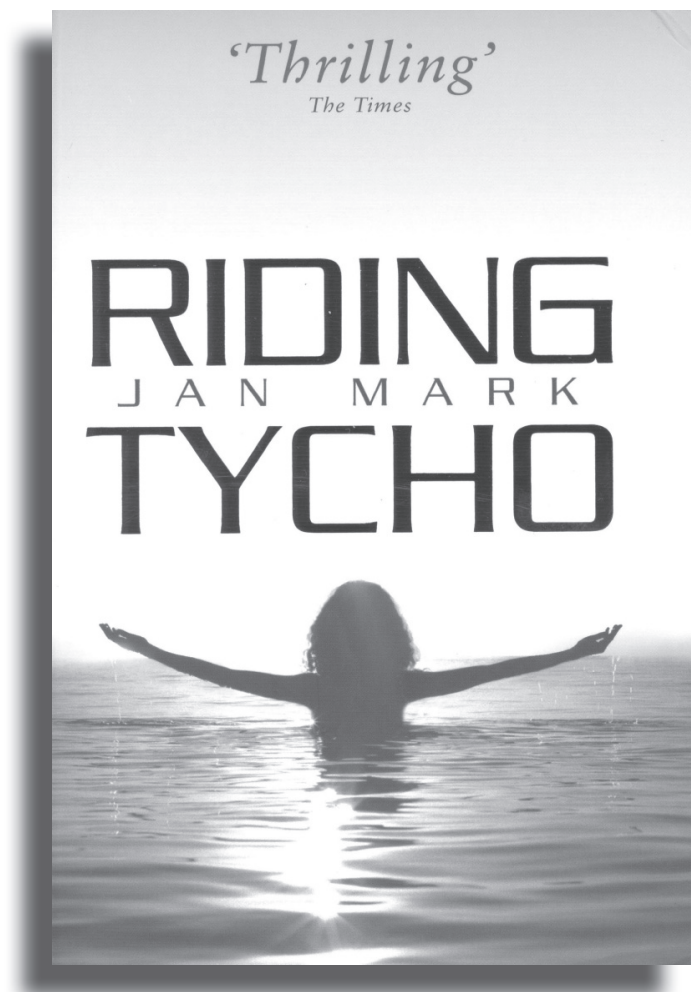

Cover of Riding Tycho by Jan Mark. London: Macmillan Children's Books, 2005 increasing migratory populations, increasingconcernsaboutsecurity, and increasing global conflict over resources would ensue from further global warming. But these factors, most evident in the flooded storyworlds of Sedgwick and Bertagna, also feature in the beginning scenes of Mark's futuristic off-world scenario as escalating violence and injustice in Demetria's small village precipitate an overwhelming need to escape further abuse. As isolation and neglect increase her marginalisation in the community, Demetria embarks upon an oceanic journey and its uncertain future. In Bertagna's flooded world, even as displaced populations hover, in the manner that contemporary "boatpeople" hover, on the oceanic verges of platform cities, tower-dwellers reside in safety. Similar to many contemporary city dwellers, the inhabitants, secure within powerful sky city structures, represent an ecological detachment which includes an ignorance of the refugees' plight. Anchored upon submerged city ruins, "New Mungo" has been founded upon a utopian vision. But the flaws in this vision, portrayed in part by restrictive control systems and high levels of surveillance, identify the dystopian frame: hidden from view, marginalised and displaced subjects remain excluded. Sedgwick's flooded world depicts similar scenes of separation, loss and anxiety as societal infrastructure fails. His protagonist, Zoe, approaches "Cathedral Island" with hopes of finding safety, but is soon trapped within a gang culture which is both dangerous and controlling. Fragmented societal connections, scarce resources, and increasing scenes of violence are indications of the cumulative effect: a loss of civilizing structures culminates in a devaluing of human connection. Hostility is similarly evident in Mark's construction of Laurentian authorities: Demetria's arrest as an enemy alien occurs as soon as the rescuing 
vessel, the Laurentia Bay, has berthed. Demetria is made aware of the country's protectionist policies in that alien unaccompanied children, considered as possible spies, are denied any legal rights and are sent to state institutions that resemble prisons.

Representations of political unrest in Mark's series are based upon ecological disagreement over policies established upon planetary settlement, a disagreement concerning resources in restricted wilderness areas. So the ecological conditions depicted by Mark, Bertagna and Sedgwick replicate concerns for contemporary refugee populations in that fears about security and increasing global conflict over scarce resources lead to the increased possibility of ongoing dislocation. These aspects of global crisis identified in United Nations research documentation (UNHCR, 2009b and IASC, 2008) inform both narrative settings and event structures in each survival quest.

\section{Climate change - the new threat to human survival.}

As concerns for environmental devastation replace global fears of nuclear apocalypse, a paradigm shift in post-disaster literatures for children and young adults has become evident. For the most part, futuristic fictions post World War II accommodated fears of nuclear apocalypse. More recently this "mutually assured destruction" (MAD) doctrine (Bradford et al, 2008, 13) has been replaced by futuristic dystopian representations that are grounded in displacement. This shift in focus is evident in the selected futuristic fictions because each oceanic survival quest embeds the refugee motif in contemporary ecological frames: the global consequences of prolonged environmental damage are clearly articulated by marginalised refugee subjects. Bertagna's image of "New Mungo"- where "branches and branches of gleaming connection" dwarf the masses of refugee vessels kept at a distance by towering walls - creates a strong mimetic of distancing strategies adopted by modern cities, a contemporary desire to remain distant from the needs of poverty stricken nations who will be first to feel the effects of global warming.

Dystopian frames, identified in depictions of control and restriction, are most evident in Mark and Bertagna's settings. Both authors portray a world order that is both governed and governing through fear. As a motif of technological superiority, Bertagna's towering sky city image creates a synecdochic alignment with other "ivory tower" motifs, linking representations of surveillance strategies with contemporary Western responses to global terrorism. 
Refugee populations outside the city experience the rigidity and violence of pun-itive systems in the same way that the penal colony, represented in Mark's series, Riding Tycho (2005), Voyager (2006), depicts extremes of segregation and abuse that soon dominate Demetria's experience of village life. Although utopian ideals of environmental preservation inform the depicted original charter agreement for the new settlement (Demeter), Mark images realistic scenes of conflict between established settlements as confrontations occur between ecological policies and developmental priorities.

Futuristic settings adopted by Sedgwick, Mark and Bertagna may once have seemed apocalyptic, but, as international acceptance of the environmental risks associated with rising ocean levels gains momentum and reports identify current ecological devastation (Warner et al, 2009:21; Boano, 2008:12) these imagined worlds signify a contemporary reality. The consequences of current warming predictions are already visible among flooded village settlements of the Tuvalu and Kiribati Islands. For low-lying nations of the Pacific, as the 2009 Maclellan report suggests, any global response to mitigate increases in global temperature will be too late: Maclellan ("The future is here", 2009) identifies the economic, social and political consequences. In these futuristic novels images of excluded refugee protagonists provide a metonymic frame for current inaction, but the contemporary realities conveyed by refugee representations are actually more dynamic as a credibility anchor to futuristic ecocritical discourse: "Millions of refugees around the world continue to live with little hope of finding a solution to their plight" (UNHCR Report, 2009b, 10).

Recent studies in utopian and dystopian narratives indicate that postdisaster fiction maintains connection with contemporary historic events as a form of moral commentary: a pattern of critique whereby depictions of the present as history permit a critical discourse arising from contemporary societal practices to speak from an imagined future (Bradford et al, 2008:13). As Bradford, Mallan, Stephens and McCallum (2008, 4-5) suggest, the new world orders posited in futuristic fiction allow spaces of transformation where both utop-ian and dystopian frames may be juxtaposed and debated. Sites of struggle in the novels of Bertagna, Mark and Sedgwick introduce what Harvey notes as a "utopian dynamic" (Harvey 2008, 189), an alternative vision which increases transformative possibilities. Thus, even as the fictional use of utopian and dystopian themes invites debate, a dialogic space is created where ecocritical perspectives may be voiced. Similarly, perceptions of agency and 
hope are created within this dialogic exchange between past and future frames where interwoven utopian and dystopian themes address an historic past (our contemporary worldview) through the lens of future need. As an interpretive mode, the refugee lens exposes the ways by which human needs and agency are restrained by existing arrangements and subsequently a dominant survival motif, empowered by quest structures, justifies a character's human aspirations to gain agency.

The problematic definition of displaced populations has been more effectively portrayed by socio-political settings in Mark and Bertagna than in Sedgwick's representation of oceanic rise. Overwhelmed by access restrictions and categorically defined as enemy alien, Demetria swiftly moves from refugee to fugitive. Conversely, Zoe,

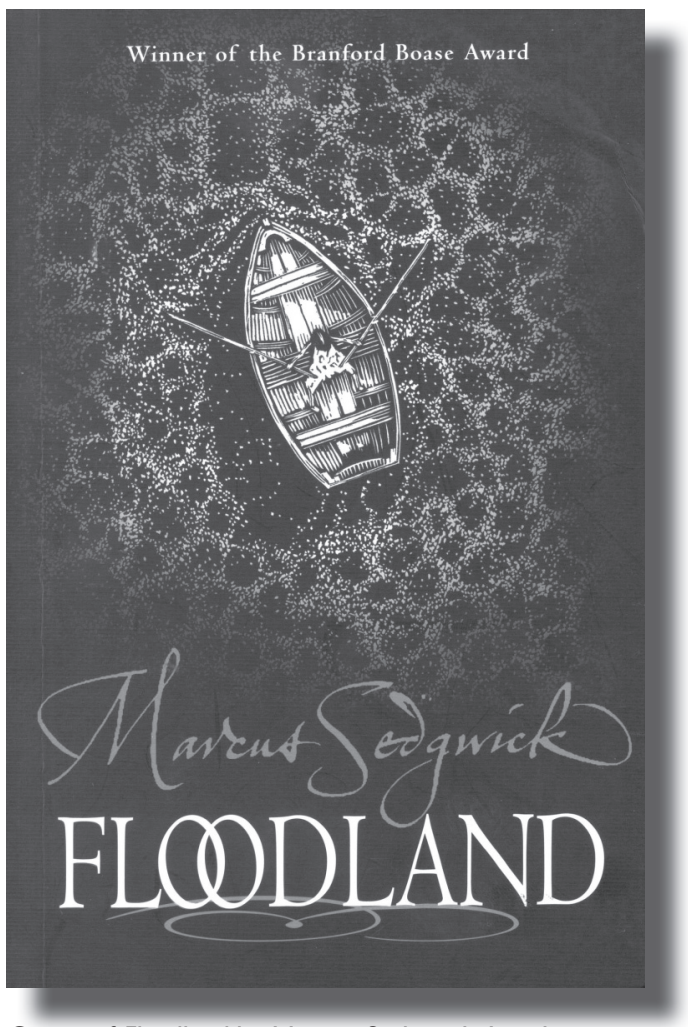

Cover of Floodland by Marcus Sedgwick. London: Dolphin Paperbacks, Orion Publishing Group, 2000 protagonist of Floodland, retains her sense of identity even as she seeks shelter within the gang culture of Cathedral Island. Her active search for reconnection with family fulfils the developmental parameters of Sedgwick's survival quest. Aspects of loss and displacement in the series Exodus/Zenith and Riding Tycho/Voyager, however, make use of the more powerful displacement motif: realistic media images inform representations of child refugees Mara and Demetria that are intensified by accurate depictions of identity loss and refugee exclusion policies.

In the refugee representations constructed by Mark and Bertagna, the loss of basic human rights depicted in these novels identifies important legal issuescommon to contemporary refugee populations. As a rising priority for appropriate refugee representation, diminished citizenship rights are acknowledged in working papers presented to research institutions for refugee studies, notably the United Nations High Commissioner for Refugees and the Refugee Studies Centre, 
Oxford University. Of particular relevance to the refugee experiences depicted by Bertagna, the Inter-Agency Standing Committee Report on climate change (2008) notes potential gaps in refugee rights of representation (IASC Working Group 2008:3). Novelistic depictions of statelessness in Mark and Bertagna thus become a powerful tool for confrontation because contrasting utopian and dystopian frames alternate between subject destitution and the corporate affluence of city spaces. An indictment of contemporary society is implied in the refugee perspectives of thesejuxtaposed spaces. Restrictive boundary controls dominate Mark's Laurentian society, where surveillance mechanisms maintain security but prevent refugee protagonist, Demetria, from establishing identity or travelling without fear of imprisonment. Restrictions are also prominent in Julie Bertagna's series where "sky city" security creates an anti-utopian space based on informational control, exclusion and surveillance. Thus the ethical integrity of a separatist utopian vision is contested because a refugee point of view promotes otherwise silenced voices.

\section{Historic remnants and narrative perspective.}

Interrogative strategies, nonetheless, must be grounded by deeper conceptual frames than child perspectives allow in order to establish an integral connection between futuristic imaginaries and contemporary issues. Speculative children's novels tend to convey naive understandings of environmental issues and rarely portray complex ecological and global economic concerns. Consequently, historic remnants may appear as crucial narratives that promote understanding. As previously mentioned, the mentor figure provides a more mature perspective from which the novel may contest the ethics of past societal practices. Importantly, mentor voices ground the author's didactic message and so clarify ecocritical perspectives. Into the liminal spaces of each refugee journey, Mark, Sedgwick and Bertagna have introduced mentor figures that not only provide opportunities to articulate environmental issues but also generate possibilities for action. In the character of Ianto Morgan (Riding Tycho), a scientist who travelled from a slowly recovering Earth to bring assistance to the new planetary settlement, Mark portrays a voice of inquiry that identifies a depleted utopian vision on the depicted new planetary settlement: "Where's it all gone?" (Mark 2006, 144) conveys a contemporary bewilderment that knowledge and diversity has such little value. Dismay, signified in the imprisoned scientist's perceptions that the realities of planet Demeter contradict thereported 
success of early colonising groups, may be voiced only in the liminal spaces of his restricted island life as a "Political". Nonetheless, representations of liminality also provide the transitional frame for action: Demetria's friendship with the scientist is conceptually confronting, but that interaction imparts the necessary strength of will to attempt an escape (Riding Tycho). Mentor figures such as Ianto Morgan and "The Pilot" (Voyager) provide Mark's protagonist with intersubjective connections that permit growth, offer relational security, and introduce agential behaviours.

The transformative utopian vision of Bertagna's series similarly emerges from the netherworld liminality of the "Treenesters". Living below the pylons of "New Mungo", Candleriggs the Elder sustains a remnant community. In this formative space Mara accepts Candleriggs' call to a new identity (Exodus), and Fox receives accurate information about the founding of the utopian city (Zenith). Identifying the wall as more than a mode of segregation, Candleriggs tells of an historic resistance movement contesting the injustice of city intentions. The city wall is metonymic of more contemporary barriers that must be confronted beforeenvironmentaljusticeissues might be solved, the same justice issues that are inherent in contemporary migration policies.

\section{Conclusion.}

Although fictional, the storyworlds of Bertagna, Mark and Sedgwick provoke a critical response to environmental degradation because refugeeimagesbothreplicateandexpandcorrespondingcontemporary issues. When the survival quest narrative becomes grounded within a critical discourse that integrates media coverage with investigative research, authors of such narratives become participants in a growing discourse of protest. Although an ecocritical discourse has become prominent in contemporary Western society, the global scope of planetary change remains a distant possibility. Even though Kyoto (2006) and Copenhagen (2009) Congresses confirm that the cumulative effects of current environmental devastation will continue to impact upon human societies during the next century ecological debate has led to limited redemptive action. Thus, when futuristic representations of planetary destruction create an imaginary by which possible scenarios may be discussed, authors reflect the capacity for literature to act as an intermediary, as Buell suggests, a form of narrative scholarship "establishing environmentality as a permanent concern about the fate of the earth" (Buell 2005, 141). Bertagna, Mark and Sedgwick assert these environmental concerns within a 
credible narrative frame primarily through focalising strategies: a refugee lens embeds contemporary issues of citizenship rights and exclusion policies in ways that interrogate societal ambivalence. It is significant that concluding scenes problematise quest traditions: the safe return home is not an option in these refugee journeys. Bertagna and Sedgwick image the very real possibility that global warming will include rising ocean levels. Their protagonists' journey toward refuge includes the hope that reconnection with family and friends may be possible. Mark's refugee protagonist, Demetria, returns to the island of her birth, but, rejecting any connection with the abusive home environment from which she previously escaped, the child "Demetria" becomes "Esperanza", and thus adopts a new identity that assumes new responsibilities.

Depicted experiences of environmental displacement and the global consequences of increasing refugee populations anchor critical perspectives in realistic, though futuristic, scenes of distress. Furthermore they interrogate societal disbelief that present ways of being will be disrupted. The authors also interrogate a common fallacy - that experiences of refugee status will be isolated to less wealthy nations. Representations of displaced children, their survival strategies, and their negotiation of new societal systems denote global distress: the plight of the refugee subject becomes an experience shared by future Western civilizations. Thus the utopian and dystopian thematic tensions that occur within futuristic fictions have a twofold purpose: primarily authors posit a cautionary tale, but, equally significant, imagined outcomes advocate hope (Sambell 2003, 163). In these survival quests Bertagna, Mark and Sedgwick create a dialogue between future possibilities and contemporary environmentalism, a dialogue made clear through intersecting utopian and dystopian modes. Within the merged frames spaces of transformation create subject depictions that affirm both the continuance of human life and possibilities for intervention even as the authors intentionally confront contemporary environmental justice issues.

Biographical information: Yvonne Hammer is (current) PhD candidate, Macquarie University, Australia. Her current research centres upon contemporary adaptations of quest structures in children's and young adult literatures. Yvonne Hammer has published a number of journal articles that focus upon her thesis topic: Mythic structure in children's literature. Contact:yhammer@bigpond.net.au 


\section{Bibliography}

Baccolini, Raffaella \& Tom Moylan. "Introduction, dystopia and histories." In Dark horizons: science fiction and the dystopian imagination. Raffaella Baccolini and Tom Moylan (eds). New York: Routledge, 2003, 1-12.

Bertagna, Julie. Exodus. London: Young Picador, 2002.

Bertagna, Julie. Zenith. London: Young Picador, 2007.

Boano, Camillo. FMO research guide to climate change and displacement. September, 2008. http://www.forcedmigration.org/guides/fmo046/ (accessed April 20, 2010).

Buell, Lawrence. The future of environmental criticism: environmental crisis and literary imagination. Carlton, Victoria: Blackwell Publishing, 1995.

Dobrin, Sydney I. and Kenneth. B. Kidd. "Introduction: Into the wild". In Wild things: children's culture and ecocriticism. Sydney I. Dobrin and Kenneth B. Kidd (eds). Detroit: Wayne State UP, 2004, 1-15.

Garrard, Greg. Ecocriticism. London: Routledge, 2004.

Harvey, David. Spaces of hope. Berkeley, Los Angeles: University of California Press, 2000.

International agency standing committee. Climate change, migration and displacement: who will be affected? Working paper submitted by the informal group on Migration/ Displacement and climate change of the IASC. 31st October 2008. http:/ / unfccc.int/resource/docs/2008/smsn/igo/022.pdf. (accessed January 20, 2010)

McCallum, Robyn. Ideologies of identity in adolescent fiction: the dialogic construction of subjectivity. London: Garland Publishing Inc., 1999.

Mc Callum, Robyn. "Young adult literature." In Vol. 4 of The Oxford encyclopaedia of children's literature. Jack Zipes (ed.). New York: Oxford UP, 2006, 214-19

Maclellan, Nic. The future is here: climate change in the pacific. Oxfam Australia \& Oxfam New Zealand. July 2009. www.oxfam.org.au/climate-change (accessed April 25, 2010)

Mark, Jan. Riding Tycho. London: Macmillan Children's Books, 2005.

Mark, Jan. Voyager. London: Macmillan Children's Books, 2006.

Moylan, Tom. Scraps of the Untainted sky: Science Fiction, Utopia, Dystopia.

Boulder, Colorado: Westview Press, 2000.

New world orders in children's literature: utopian transformations. Bradford, Clare, Kerry Mallan, John Stephens, and Robyn McCallum (eds). Hampshire: Palgrave Macmillan, 2008.

Sambell, Kay. "Presenting the case for social change: the creative dilemma of dystopian writing for children." In Utopian and dystopian writing for children and young adults. Carrie Hintz \& Elaine Ostry (eds). New York: Routledge, 2003, 163-178. 
Sedgwick, Marcus. Floodlands. London: Dolphin Paperbacks, Orion Publishing Group, 2000.

Stephens, John. "Postdisaster fiction: problematics of a genre." Papers:

explorations into children's literature, 3 (1992) 3: 126-30. Stephens, John. Editorial. In International research in children's literature 2.2, 2009.

United Nations high commissioner for refugees, international organization for migration, United Nations university. Climate change, migration, and displacement: impacts, vulnerability, and adaptation options. 6th February, 2009a. http://www.globalmigrationgroup.org/pdf/CL_change_M_Displacement_by_IOM_UNHCR_UNU.pdf. (accessed April 20, 2010).

UNHCR Report submitted by the Field information and Coordinated support section. 2008 Global trends: refugees, asylum seekers, returnees, internally displaced and stateless persons. UNHCR, Geneva, $16^{\text {th }}$ June, 2009b. http:/ / www.unhcr.org/4a375c426.html (accessed January 15, 2010)

Warner, Koko, Charles Ehrhart, Alex De Sherbinin, Susana Adamo and Tricia Chai-Onn. In Search of shelter: mapping the effects of climate change on human migration and displacement 2008. Co-operative for assistance and relief everywhere, Inc. (CARE) May, 2009. http:/ / issuu.com/careandclimatechange/docs/care_in_search_of_shelter (accessed April 25, 2010).

Zapf, Hubert. "Literary ecology and the ethics of texts". In New literary history 39 (2008) 4: 847-868. 